Edvânia Ângela de Souza Lourenço ${ }^{1}$ Íris Fenner Bertani²

\section{Saúde do trabalhador no SUS: desafios e perspecti- vas frente à precarização do trabalho}

\author{
Workers' health at the Public Unified Health System - challenges \\ and perspectives facing precarious work
}

1 Doutoranda em Serviço Social da Universidade Estadual Paulista (Unesp). Assistente Social do Centro de Referência em Saúde do Trabalhador (CRST) de FrancaSP. Docente do curso de Serviço Social do Instituto Municipal de Ensino Superior-SP. Membro do QUAVISSS. Franca-SP.

2 Professora Adjunta da Graduação e da Pós-Graduação em Serviço Social da Universidade Estadual Paulista (Unesp) e Coordenadora do QUAVISSS. Franca-SP.

\begin{abstract}
Resumo
Refletir sobre o campo saúde do(a) trabalhador(a) é o objetivo deste estudo. Busca-se sublinhar o significado das condições de trabalho para o ser humano do ponto de vista da saúde. A premissa não é quantificar, mas inferir que as condições de trabalho podem gerar danos à saúde, mas nem sempre apresentam de imediato a sua relação com o trabalho. São discutidas, a partir da abordagem qualitativa, três situações, as quais contemplam os trabalhos rural, informal e infantil e, como resultado, verifica-se a contradição da categoria trabalho, que, se por um lado é sinônimo de sociabilidade, por outro, contraditoriamente, constitui-se em mecanismo de exclusão social na medida em que é realizado sem o reconhecimento dos direitos sociais e trabalhistas. Verifica-se a expansão de formas de trabalho sem regulamentação, tais como o domiciliar e o familiar e os realizados em locais como a rua e o lixo. Encerra-se a reflexão com destaque ao papel do Sistema Único de Saúde (SUS) na "assistência integral” à saúde dos(as) trabalhadores(as) e ao desafio de atuar na perspectiva de prevenção e promoção da saúde do trabalhador de modo integrado e articulado aos demais órgãos públicos que atuam nesta área.
\end{abstract}

Palavras-chave: saúde do trabalhador, acidentes de trabalho, doenças do trabalho, saúde pública e políticas públicas.

\begin{abstract}
The objective of this study is to ponder on occupational health, searching for the meaning of work to workers' health. The premise is not to quantify, but to infer that the work conditions can generate damages to health, although this relationship is not always immediately apparent. Three situations that contemplate rural and informal work, as well as child labor are discussed, using a qualitative approach. As a result, the contradiction of work is verified. It could be a synonym for sociability, but on the other hand, it is a mechanism for social exclusion, when conducted without the recognition of the workers' social and labor rights. The expansion of jobs without regulation have been observed such as the ones conducted at home or within families, or on the streets and at the waste landfills. The article ends by discussing the role of the Public Unified Health System (SUS) in the "integral assistance" to workers' health and the challenge of acting with a preventive perspective and towards occupational health promotion, in a joint effort with other public organization in this field.
\end{abstract}

Keywords: occupational health, work accidents, occupational diseases, public health and public policy. 


\section{Introdução}

\section{O SUS e o campo saúde do trabalhador}

As ações de saúde do trabalhador têm as suas raízes no processo histórico das lutas sociais deflagradas no Brasil a partir da década de 1970, mas ações inusitadas começaram a ganhar corpo apenas na década de 1980 nos governos municipais de ênfase política democrática.

Pode-se perceber uma relação entre a redemocratização do Estado brasileiro no decorrer dos anos de 1980 e a mudança de postura política no enfrentamento dos eventos agressivos à saúde no trabalho. Segundo Vilela (2003), nessa época foram constituídas as primeiras ações de saúde do trabalhador no âmbito do SUS por meio dos Programas de Saúde do Trabalhador (PST) em vários municípios.

Segundo Lacaz (1996), a década de 1980 representa um marco histórico para a saúde do trabalhador, pois este passa a ser reconhecido como sujeito possuidor de saber e não mero consumidor de serviços de saúde. O campo Saúde do Trabalhador, segundo o autor, tem como pressuposto a participação dos(as) trabalhadores(as) no processo de avaliação e controle dos acidentes de trabalho e não se restringe à concepção de riscos profissionais e agentes causadores (físicos, biológicos, químicos, mecânicos e ergonômicos), mas reconhece outras determinações para os sofrimentos físico e mental, relacionando-as com o processo produtivo.

Em seu estudo, Lacaz (1996) enfatiza ainda o papel substancial da Constituição Federal de 1988, precedida pela VIII Conferência Nacional de Saúde, em 1986, e na continuidade pela $1^{\mathrm{a}}$ Conferência Nacional de Saúde do Trabalhador (I CNST), na assistência universal ao trabalhador acompanhada da prevenção e da intervenção nos ambientes de trabalho.

A Carta Constituinte (BRASIL, 1988) estabelece parâmetros legais para a constituição do campo saúde do trabalhador no Sistema Único de Saúde (SUS). Seu artigo 200 estabelece a ampliação do atendimento do SUS para além da intervenção no corpo ou suas partes; evolui para a intervenção nas causas e, inclusive, nos ambientes de trabalho, como verificado no inciso II “executar as ações de vigilância sanitária e epidemiológica, bem como as de saúde do trabalhador" e no inciso VIII "colaborar na proteção do meio ambiente, nele compreendido o trabalho".

Na década de 1990, diversas portarias e leis foram criadas com o objetivo de garantir os princípios básicos e a efetivação do SUS. No decorrer dos últimos 15 anos, apesar dos limites marcados pelo clientelismo, populismo e paternalismo presentes na administração pública, o SUS tem conseguido solidificar as bases para o direito à saúde com ênfase na gestão democrática e participativa.

Os protagonistas sociais e políticos envolvidos na II Conferência Nacional de Saúde do Trabalhador (II CNST) debateram e reafirmaram a responsabilidade do SUS frente aos acidentes de trabalho. O relatório final do II CNST garantiu “[...] à unificação no SUS de todas as ações de saúde do trabalhador" (LACAZ, 1997). É reconhecida também pela continuidade das discussões técnicas e políticas na constituição do campo saúde do trabalhador e, portanto, para a observância da responsabilidade da política de saúde pública nos processos de produção. Dias e Hoefel (2005, p. 820), apontam que esta conferência também foi marcada pela "[...] acirrada disputa quanto aos espaços de atuação entre os Ministérios do Trabalho e da Saúde”.

No final de 1990, em cumprimento a Lei Orgânica da Saúde (BRASIL, 1990b), que delega ao SUS a revisão periódica da listagem oficial de doenças originadas no processo de trabalho, foi editada a nova Lista de Doenças Relacionadas ao Trabalho (BRASIL, 1999). Ressalta-se que, ao estabelecer a relação entre doenças e trabalho num conceito mais amplo e prever a sua revisão anualmente com vistas à inclusão de novas doenças, propiciou um avanço para novas práticas e políticas no campo saúde do trabalhador.

Outro aspecto positivo possibilitado pela edição da Lista de Doenças Relacionadas ao Trabalho é o fato de ter sido adotada também

pelo Ministério da Previdência e Assistência Social, regulamentando o conceito de Doença Profissional e de Doença Adquirida pelas condições em que o trabalho é realizado [...]. (DIAS, 2001, p. 20)

Desse modo, a doença relacionada ao trabalho para fins de benefícios pode ser equiparada ao acidente de trabalho (BRA- 
SIL, 1991). Assim, a legislação utiliza a expressão acidentes de trabalho para se referir também às doenças relacionadas ao trabalho. Contudo, optou-se por utilizar o termo agravos à saúde por considerá-lo mais abrangente.

A participação política de trabalhadores e demais atores sociais é responsável pelas definições dos elementos de incentivo, tanto econômicos como ideológicos, do Ministério da Saúde (MS) para implantação concreta dessa área do conhecimento e de intervenção, a qual passa a ter condições concretas de ser efetivada a partir da publicação da Portaria 1679/2002 (BRASIL, 2002), que normatiza a "habilitação" e o convênio entre os municípios, o Estado e o MS para a implantação dos Centros de Referência em Saúde do Trabalhador (CRST) em âmbito regional.

A incorporação da saúde do trabalhador pelo SUS reconhece, nos ambientes e processos de trabalho, as condições para os eventos agressivos à saúde "de quem trabalha" na perspectiva epidemiológica. Não se restringe a atender o lesionado individualmente, mas busca quantificar o número de pessoas expostas à insegurança e qualificar essas condições para posteriores mudanças.

\section{Saúde do trabalhador: por quê?}

Não há uma resposta única para defender a emergência e a solidificação do campo saúde do trabalhador no SUS, mas a legitimidade desta proposta se constitui por meio de vários pressupostos, como, por exemplo, que os serviços de saúde já prestam atendimentos aos agravos, sendo necessário buscar as suas causas e nelas intervir, ou seja, transcender as ações curativas para as de prevenção, promoção e vigilância em saúde do trabalhador. Outros fatores relacionam-se à abrangência territorial do SUS e ao número de equipes profissionais capazes de desenvolver ações voltadas à saúde do trabalhador. Inúmeras outras questões poderiam ser elencadas, mas frisa-se, além dessas, a questão da democracia e da epidemiologia, as quais têm materializado avanços para as ações de saúde. Então, defende-se a inclusão, no contexto do SUS, das ações relativas aos agravos à saúde de quem trabalha por acreditar-se que favorece a redução do vácuo entre o indivíduo que sofre o acidente de trabalho e as condições em que é realizado, ou seja, deixa de ser uma "suscetibilidade" individual para ser situado como uma questão de saúde coletiva, fruto das condições e da organização do trabalho.

Lacaz (1996, p. 54) indica que no campo saúde do trabalhador:

[...] o coletivo de trabalhadores é percebido como produtor e não mais consumidor de condutas, prescrições/orientações, medicamentos etc.

Portanto as ações devem ser socializadas e integradas a quem mais interessa melhorar as condições de saúde: os próprios trabalhadores.

Neste aspecto, os CRST têm envolvido a sociedade com a discussão da questão saúde/trabalho. A habilitação do CRST exige a formação de um Conselho Gestor e, neste, as entidades representativas da classe trabalhadora e patronal, dentre outras, são convidadas a pensar-agir sobre as questões locais referentes à saúde do(a) trabalhador(a).

Além da participação dos(as) trabalhadores(as), Lacaz (1996) aponta a abordagem multi e interdisiciplinar presente no campo saúde do trabalhador. A análise e o enfrentamento cotidianos da complexidade dos processos de trabalho para a saúde passam a contar com novas categorias profissionais, o que representa um avanço, à medida que se distancia do diagnóstico/ ação restrito à engenharia e à medicina.

Assim, a Rede Nacional de Atenção Integral à Saúde do Trabalhador (RENAST), por meio dos CRST, tem implantado uma nova lógica de trabalho nos vários municípios brasileiros baseada na construção de ações intersetoriais entre os serviços de saúde, como a rede básica e as vigilâncias epidemiológica, ambiental e sanitária, e prevê ações coordenadas com os órgãos de atuação nos ambientes de trabalho (Posto de Atendimento ao Trabalhador (PAT), Delegacia Regional do Trabalho (DRT), Fundação Jorge Duprat Figueiredo de Segurança e Medicina do Trabalho (Fundacentro), Ministério Público (MP), Instituto Nacional de Previdência Social (INSS) e outros).

A atualização permanente de conhecimentos da equipe técnica dos CRST também faz parte da diretriz da política nacional de saúde do trabalhador, bem como a participação dos(as) trabalhadores(as), considerada essencial para o diagnóstico dos riscos e, concomitantemente, para intervenção e mudança. 
Dias e Hoefel (2005) expõem que é também proposta da RENAST coletivizar a questão dos acidentes e adoecimentos relacionados ao trabalho por meio do registro desses eventos no sistema de informação, o que possibilita a identificação dos fatores de risco e a orientação das ações de vigilância.

Contudo, na prática, há uma enorme contradição entre ações assistenciais aos(às) trabalhadores(as) que sofreram acidentes de trabalho e a nova proposta da RENAST. Isto é, a discussão sobre a responsabilidade do SUS na intervenção sobre os processos de trabalho, debatida na II CNST (1994) e ampliada na III CNST (2005), ainda não foi esgotada, especialmente no que tange à inspeção, o que não pode ser tratado como algo desprezível na efetivação do campo saúde do trabalhador.

$\mathrm{O}$ que se verifica nos dois anos de funcionamento do CRST de Franca-SP, ao se considerar a realidade regional, é o início da práxis no campo saúde do trabalhador. Há um esforço para construir dados fidedignos sobre os acidentes e as doenças relacionadas ao trabalho e, a partir destes, estabelecer as ações. Porém, ainda ocorre uma dificuldade de entendimento sobre "de quem é a responsabilidade de fiscalizar, inspecionar, conter e prevenir os acidentes de trabalho, o que resulta em visível omissão de ação" (LOURENÇO \& BERTANI, 2006, p. 50).

Apesar do campo saúde do trabalhador ter sido construído com a participação de vários atores sociais e políticos e de ter sido reconhecido no plano legal, não foram efetivadas novas práticas para além da assistência médica, salvo algumas ações inusitadas, mas ainda focais.

Refletir sobre a saúde do trabalhador no SUS significa sublinhar uma área de conhecimento em construção e que se propõe a compreender as manifestações das condições de trabalho para a saúde não apenas na esfera dos acidentes de trabalho no âmbito industrial, mas também a sua repercussão, do ponto de vista da saúde, no campo da agricultura e dos serviços (MINAYO-GOMES \& LACAZ, 2005).

Trata-se de um modelo, como aborda Lacaz (1996), em construção, mas que, segundo Minayo-Gomes e Lacaz (2005), ao longo de vinte anos, desde as primeiras experiências, apresentou um impacto de pouca visibilidade frente à complexidade do modo de produção e seus efeitos para a saúde dos(as) trabalhadores(as). Os autores reforçam o avanço que representa a institucionalização das ações de saúde do trabalhador no âmbito do SUS, mas criticam a falta de êxito relativa à proposta inicial quanto à articulação com a rede básica e o suporte técnico e especializado oferecido pelos CRST no projeto original do Programa de Saúde do Trabalhador (PST).

Às dificuldades culturais, ideológicas e políticas no estabelecimento de ações eficazes no campo da saúde do trabalhador somam-se as mudanças do mundo do trabalho e a opção do Estado pelo projeto neoliberal de governo.

A precariedade das condições de trabalho manifestada na violação dos direitos trabalhistas, na insegurança do posto e do ambiente de trabalho, no aumento do ritmo da produção e das exigências (pressão) interfere na saúde dos(as) trabalhadores(as) e também no modo de agir, pensar, sentir e fazer ou, nas palavras de Antunes (1999, p. 15), na "subjetividade da classe trabalhadora”.

Antunes (1999) mostra que houve uma processualidade contraditória, ou seja, a mudança radical na organização do sistema de produção, marcada pela reestruturação produtiva, pela terceirização e pela flexibilização, resultou, por um lado, na redução do operariado industrial e fabril e, por outro lado, na subproletarização do trabalho expressado nas formas de trabalho parcial, precário, temporário, informal, entre tantas modalidades existentes.

Tudo isso corrobora a inflexão do movimento sindical e a pulverização da classe trabalhadora que, no início do século XXI, trava esforços para manter o emprego e gera um retrocesso histórico ao se distanciar da melhoria das condições de trabalho.

Desse modo, o fenômeno dos acidentes de trabalho passa a representar uma nova demanda à medida que não se restringe ao setor formal de caráter industrial, mas atinge o informal, com forte predominância do setor de serviços. Os desempregados, os aposentados e, ainda, crianças e adolescentes trabalhadores constituem "novos" problemas de saúde. Este fenômeno está imbricado com uma contraditória e complexa estrutura presente nas diferentes formas de produção e perpassa a economia familiar, a formal, as empresas arcaicas e até as mais modernas. Portanto, é necessária uma ação coordenada que busque as causas e que nelas interfiram. 
A forma fenomênica de apresentação dos agravos relacionados ao trabalho não trazem à tona, de imediato, as condições concretas a que a maioria dos(as) trabalhadores(as) está inserida. Assim, a terminologia "saúde do trabalhador" está envolta pela compreensão mais ampla da realidade, considerada aqui como um todo que tem uma estrutura construída com partes que se relacionam entre si, dinâmica e mutável. O olhar para a realidade está sujeito a várias interferências. Assim, a negação da aparência inicial e as mediações tornam-se importantes no processo de investigação e ação.

Apreender as condições de trabalho de modo interdisciplinar e coletivo para reconstruí-las racionalmente é um desafio dialético, materialmente necessário para qualificar a questão dos acidentes de trabalho, caracterizando-os como elementos constitutivos da lógica reprodutiva do sistema capitalista e jamais como uma questão individual ou como "fatalidade do destino".

Para Minayo-Gomez e Lacaz (2005), o uso da expressão "saúde do trabalhador" está norteado pela compreensão mais ampla da realidade que - na acepção marxista - tem como núcleo básico o "processo de trabalho". Explicitam o alto poder explicativo do processo de trabalho na gênese dos agravos à saúde:

[...] A análise dos processos de trabalho é uma ação teórico-prática potente, pois permite identificar as transformações necessárias a serem introduzidas nos locais e ambientes para a melhoria das condições de trabalho e saúde. (Minayo-Gomes \& Lacaz, 2005, p. 799)

Minayo-Gomez e Lacaz (2005) acrescentam que a análise da saúde do trabalhador nas dimensões do "processo de trabalho" requer um tratamento interdisciplinar que dê conta de abranger as relações de produção e a subjetividade dos vários atores sociais nelas envolvidos. Isso ajuda a romper as análises positivistas e simplificadas de causa e efeito hegemônicas na medicina do trabalho e na saúde ocupacional.

Os avanços, contidos na Constituição Federal de 1988 e nas legislações subseqüentes, que garantem a saúde e a segurança no trabalho, chocaram-se com as mudanças do mundo do trabalho, ampliadas a partir da década de 1990, que repercutiram, entre outras coisas, em agravos à saúde humana. Portanto, não é possível efetivar o campo saúde do trabalhador com atendimentos centrados apenas no caráter das esferas biológica e individual. Há de se considerar o processo de trabalho e as relações por ele estabelecidas no tocante às incapacidades permanentes e temporárias.

O olhar epidemiológico deve ser colocado em prática e o SUS, pela sua capilaridade, pode avançar na questão da saúde/trabalho. O sistema de informação pode dar visibilidade teórica e empírica às reais condições de trabalho e, assim, reverter a cultura de que o trabalho é bom independentemente das condições em que é realizado.

Ao indagar sobre o campo saúde do trabalhador como área de intervenção do SUS, pretendeu-se evidenciar o papel dos serviços de saúde não apenas na assistência ao problema de saúde apresentado pelo(a) trabalhador(a), mas, sobretudo, na intervenção das causas a partir dos princípios do SUS: universalidade, integralidade, descentralização e participação.

\section{Acidentes de trabalho: uma forma de ex- clusão social}

Consideram-se os acidentes de trabalho como um modo de exclusão social. Salienta-se que o uso do termo "exclusão social" não é usado para designar a pobreza e a desigualdade, mas cunha-se à linha adotada por Ammann (2003), a qual não se preocupa em estabelecer uma conceituação fechada da exclusão social e faz uso de estudos atuais acerca da temática para justificar que tal expressão sugere um estado de privação, mas não recupera, historicamente, os processos que a engendram. Assim, Ammann (2003) discute algumas linhas que demarcam o tema e adota a postura marxista de centralidade ontológica do trabalho, na qual sublinha o papel fundante do trabalho na afirmação do ser social e sua determinação nos processos históricos que geram ou não a exclusão social.

A aproximação dos acidentes de trabalho como uma forma de exclusão social se dá à medida que estes favorecem a ruptura e a desagregação social, como apontam Cohn, Karsch e Sato (1985) no estudo sobre os acidentes de trabalho como uma forma de violência. Os autores expõem que as incapacidades permanentes direcionam o trabalhador rumo à miséria, "ao estatuto de inválido e, portanto, de força de trabalho sucateada no mercado" (p. 12). 
Exclusão social se dá não apenas pelo desemprego ou pelos baixos salários, mas no sentido da inacessibilidade aos direitos sociais. Um tipo de exclusão foi denunciado por Engels (1985) como "exército industrial de reserva”, referente ao desemprego provocado sobretudo pela substituição do homem pelas máquinas no final do século XIX. O autor mostra que o desemprego no início da Revolução Industrial tornou-se funcional ao sistema capitalista e nocivo para aqueles que estavam inseridos no mercado de trabalho, pois as pessoas desempregadas se viam obrigadas a aceitarem qualquer trabalho por um valor ínfimo.

A exclusão social da atualidade expõe pessoas como "desprezíveis" do ponto de vista da concorrência do mercado de trabalho, vive-se a "era tecnológica" e suas mudanças são tantas que se torna difícil acompanhá-las. Assim, aqueles que não têm acesso, mesmo que minimamente, à educação e à cultura, também não encontram chances para concorrer no competitivo mercado, em que trabalho (formal) é uma raridade.

Pochmann (2006) mostra o aumento do desemprego: “[...] Em 2002, por exemplo, o país registrou a quarta posição no ranking mundial do desemprego" (p. 60). Aponta também que o número de ocupações criadas, inferiores às extintas e ainda marcadas pelo processo de reestruturação e flexibilização do setor produtivo, não garantem os direitos trabalhistas previstos, pois “[...] nos anos 1990, a cada dez empregos criados, somente quatro foram assalariados" (p. 61).

O desemprego, a reestruturação e a flexibilização da produção são particularidades em constante relação com os aciden-

\section{Metodologia}

Busca-se, com o relato das situações a seguir, identificar a origem da manifestação dos agravos à saúde humana relacionados ao trabalho. Distancia-se da causa natural da doença ou dos agentes causadores. Da mesma forma, não se trata de apresentar dados estatísticos, mas discutir as condições de trabalho que interferem na saúde dos(as) trabalhadores(as) e o papel do SUS neste processo.

O método utilizado foi a observação da realidade empírica de três situações que versam sobre as condições de trabalho e tes de trabalho. As precárias condições de trabalho acompanhadas de perto pela ameaça do desemprego geram instabilidade, insegurança e risco social e de acidentes que, imbricadas com o aumento da pobreza e da desigualdade social, agravam a exclusão social.

Assim, a saúde do trabalhador deve se aproximar das condições de trabalho não apenas do mercado formal, mas, sobretudo, dos autônomos, das produções independentes, familiares ou de cooperativas. Nas palavras de Minayo-Gomes e Lacaz (2005, p. 806): "faz-se urgente conhecer, diferenciar e atender o setor informal e o mundo difuso e desprotegido dos desempregados".

Dejours (2005), no estudo sobre a banalização da injustiça social, aponta que pode haver uma dualidade do sofrimento pelo trabalho. Por um lado, há os que sofrem os efeitos da exclusão do mercado de trabalho, que refletem na degradação das condições de vida, expressa, entre outros, no aumento de moradores de rua, de periferias, e nos holofotes da violência, da marginalidade, da desnutrição, da subnutrição e dos mais diversos conflitos e doenças sociais. Por outro lado, estão aqueles inseridos precariamente no mercado de trabalho e expostos às condições insalubres, inseguras e de risco para as saúdes física e mental. São estes últimos os enfoques deste estudo, uma vez que, a rigor, as condições de trabalho podem ser retratadas na história das incapacidades permanentes ou temporárias e pela miséria social provocada e reafirmada por este processo. Assim, lança-se mão da descrição e da análise de três situações que, além do acidente de trabalho em si, representam a relação das condições do trabalho com a saúde.

seus reflexos para a saúde, materializadas, neste estudo, por meio de entrevistas abertas sem roteiro prévio, mas com referencial temático definido. A escolha das situações privilegiou os possíveis efeitos das condições adversas de trabalho, nem sempre transparentes, como uma questão de saúde pública.

Desse modo, uma das situações apresentadas refere-se à questão do acidente de trabalho propriamente dito, ocorrido em 26/06/1996, explicitado pela história do trabalhador rural, Aparício da Silva (nome 
fictício), em acompanhamento social no CRST de Franca-SP, que se prontificou a ser sujeito desta reflexão a partir do Consentimento Livre e Esclarecido.

Na continuidade da reflexão, enfocase o trabalho informal realizado em um depósito de catadores de lixo, situado em Brasília-DF, em condições de possíveis agravos à saúde. Este foi escolhido, exatamente, por representar a flexibilidade do mercado de trabalho acompanhada da precarização das condições em que é realizado e seus possíveis reflexos, ainda no anonimato, para a saúde.

Assim, a escolha da segunda situação se deu, justamente, por representar a complexidade das mudanças no mundo do trabalho em um momento de avançada discussão sobre a relação entre trabalho e saúde ocorrida na III CNST, em novembro de 2005. Nesse período, realizou-se visita ao local, depósito de lixo coletado por catadores, e entrevistou-se uma das famílias que concordou em fazer parte desta reflexão.

Reforça-se que a preocupação com o aumento da informalidade, do trabalho autônomo, "por conta", e as possíveis repercussões para a saúde presente e futura dos(as) trabalhadores(as) norteou a escolha da situação do trabalhador que, junto com a sua família, residia no local em que se depositava lixo recolhido para posterior seleção do que poderia ser comercializado por eles.

Na seqüência, aborda-se outro aspecto degradante, que é o trabalho infantil como uma forma de violência social. A escolha desta questão se deu por observar que, apesar da avançada legislação brasileira, o trabalho infantil ainda faz parte das particularidades do mercado de trabalho nacional, controlado no setor industrial, mas real no mercado informal, conforme observado em festividades em locais públicos no município de Franca e também em praias da região norte do Estado de São Paulo durante o segundo semestre de 2006.

\section{Apresentação dos casos}

\section{Situação 1: A invisibilidade social dos} acidentes de trabalho

Aparício trabalhava numa importante fazenda de criação de gado em um município próximo a Franca-SP. O mesmo perdeu a perna esquerda durante o exercício do seu trabalho, aos 25 anos de idade. O trabalhador enfrenta a situação dolorosa da deficiência física provocada pelo trabalho e também pela conseqüente exclusão deste.

Aparício refere que no dia do acidente trabalhou durante o período noturno "arando" terra e parou por volta das 4 horas da manhã. Ao guardar o maquinário (trator), foi abordado pelo empregador que lhe pediu para moer o "trato" do gado, uma vez que o funcionário responsável por essa função havia faltado. Segundo ele, tentou argumentar que estava cansado, mas diante da insistência, assumiu a função. Lembra que o tempo estava chuvoso e o chão escorregadio, estava sozinho manuseando a máquina de moer "trato" para o gado quando escorregou e teve a sua perna puxada pela máquina:

Não sei direito o que aconteceu, mas graças a Deus que a máquina travou. Eu tentei não dormir, porque estava sozinho, fui socorrido por um colega por volta das 8 horas e isso aconteceu a pouco mais das 4 horas, então não sei como não morri. (Aparício)

O trabalhador foi socorrido e levado pelo Serviço de Resgate à Santa Casa de Franca. Lá recebeu todos os cuidados e orientação quanto à Comunicação de Acidente de Trabalho (CAT). Mas, ao solicitar a CAT ao empregador, foi convencido de que não era necessário, pois eles (empregadores) lhe dariam tudo o que precisasse. Na época residia com a sua mulher e os três filhos em casa de propriedade da fazenda onde era funcionário: "Achei por bem seguir a orientação do patrão e não mexi mais com isso, com a CAT” (Aparício).

Aparício foi periciado inúmeras vezes no Instituto Nacional de Seguro Social (INSS) e, segundo ele, sempre relatou o motivo da perda da perna. Após ter conseguido, em 1998, a perna mecânica via SUS (Programa de Órtese e Prótese do Núcleo de Gestão Assistencial - NGA), deixou de receber do INSS um salário mínimo integral e passou a receber apenas uma parte, equivalente, atualmente, a $\mathrm{R} \$ 119,00$ (cento e dezenove reais) por mês, uma vez que, na visão do seguro social, ele teria condição de trabalhar.

Contudo, para o empregador, ele não servia mais para trabalhar em nenhuma função. Após um tempo do ocorrido, foi dispensado. Os empregadores venderam a fazenda e se mudaram para a região de Mato Grosso do Sul.

O fato é que, mesmo sendo jovem, a deficiência física associada à falta de edu- 
cação formal limitou as possibilidades de inserção no mercado de trabalho:

Ficou muito difícil porque fui criado na roça e é só isso que sei fazer. Eu andei arranjando alguns serviços, mas logo não me pegavam mais, alegavam que era perigoso e que eu poderia me machucar de novo. (Aparício)

O desemprego, a falta de moradia, a deficiência física (desencadeada pelo acidente de trabalho) levaram Aparício a enfrentar sérias dificuldades econômicas e sociais que, dentre outros, favoreceram a dissolução familiar. Sua esposa mudou-se para Franca, com seus três filhos, em busca de emprego e melhores condições de vida. Aparício passou a residir de favor com o pai, que é idoso.

Situação 2: A informalidade e a invisibilidade social dos possíveis acidentes de trabalho

A informalidade entrelaça as pessoas no mundo do trabalho sem muitas condições de questionamentos e mudanças do que está posto e pode conferir aos seus trabalhadores extrema vulnerabilidade de saúde e de vida.

A análise da situação da família de Dona Cleuza e Seu Manoel (nomes fictícios) traz à tona a precariedade das condições de trabalho e também de vida das várias famílias brasileiras que sobrevivem do lixo.

Um breve sumário da sua história mostra um lado do trabalho totalmente inseguro do ponto de vista de possíveis contaminação, ferimentos, adoecimentos, da saúde mental no trabalho e, ainda, do trabalho infantil.

O casal está em Brasília há 15 anos. Oriundos da Bahia, vieram em busca de melhores condições de vida, mas, devido à ausência de documentos, de escolaridade, de profissão e de condições financeiras, não conseguiram emprego ou outro modo de sobrevivência. A família não conta com nenhuma documentação, inclusive dos filhos; por esse motivo, segundo eles, não estão cadastrados em nenhum programa social federal, como bolsas escola, família ou alimentação. Sobrevivem com os filhos juntando e separando lixo (orgânico, contaminado etc.) para a seleção de materiais (papel, plástico etc.) a serem comercializados.

O filho mais velho, 15 anos, percorre as ruas de Brasília empurrando um "carrinho de mão” da família, em busca de papel ou outros materiais recicláveis, enquanto seus pais permanecem no local - um terreno baldio - onde depositam o material arrecadado para posterior seleção.

Trata-se de um trabalho degradante realizado no meio do lixo. O que foi descartado por outrem é aproveitado por eles por uma questão de sobrevivência. Observa-se que Dona Cleuza, enquanto separava o lixo, amamentava a filha mais nova, de 2 anos, que estava completamente nua. A outra filha, de 5 anos, tentava saborear os farelos de resto de um pacote de salgadinhos encontrado no lixo. Outros dois filhos com idades ente 6 e 7 anos permaneciam ao lado do pai observando a lida.

Não há uma separação entre a casa e o ambiente de trabalho. Ergueram barracos de plástico para permanecerem junto ao "lixo" e evitarem roubos ou destruição do material arrecadado:

Às vezes, alguém pode destruir por bagunça mesmo ou roubo, mas os homens (do governo) destroem para a gente ir embora daqui, mas não podemos ir porque não teria como sobreviver. (Manoel)

Ao se considerar que há uma relação intrínseca entre trabalho, meio ambiente e saúde, talvez este seja o retrato da degradação socioecológica. O ambiente estava carregado pelo mau cheiro dos restos de comida e sujeiras próprias do lixo que atraía uma nuvem de mosquitos, infestando o local. A casa improvisada (barraco de plástico) não oferecia proteção nem conforto aos seus habitantes. Do lado de fora, um pequeno fogão, também improvisado, feito com tijolos, trazia as panelas postas com restos de alimentos sujeitos à deterioração devido ao armazenamento e à conservação inadequados, misturandose ao lixo. O ser humano encontra-se aí, no seu ambiente de trabalho, vulnerável a possibilidades de contaminação e aquisição de doenças e acidentes. Contudo, a relação com o trabalho permanece na invisibilidade social.

Outra questão observada nessa situação é o trabalho infantil e a falta de proteção do trabalho do adolescente. Há um processo cultural instalado pela própria convivência diária das crianças com esse modo de trabalho que representa, entre outros, elementos configuradores para o trabalho infantil e para a naturalização da cultura do trabalho independentemente das condições em que é exercido. 


\section{Situação 3: Trabalho infantil}

Apesar de contar com uma legislação que proíbe o trabalho infantil e que protege o trabalho do adolescente, é comum encontrar crianças "ajudando" no orçamento familiar, como o caso do filho de 15 anos de Dona Cleuza e Seu Manoel. A questão do trabalho infantil deve ser analisada a partir de um contexto mais amplo que inclua a questão da cultura, da política e das condições socioeconômicas.

Evidencia-se, neste estudo, o trabalho de crianças que exercem funções como a de "guardador de carros" (para designar a função de olhar, "vigiar" enquanto o dono se ausenta, situação comum nos estacionamentos públicos), "vendedor ambulante" (designação para a venda de produtos como água, latinhas de cerveja, balas, chocolates etc., situação comum no trânsito e em festividades) e catador de produtos recicláveis (papel, latinhas de alumínio e outros). As crianças nas condições de trabalho referidas, quando questionadas sobre a atividade, mudaram de assunto e de lugar, despistando o nosso olhar, com exceção do menino de 6 anos "guardador de carros".

A fala do menino de 6 anos de idade, "guardador de carro", quando perguntado sobre a atividade, respondeu: "Estou trabalhando para ajudar minha avó”. Demonstra uma imagem de preocupações travestidas na responsabilidade de manutenção da vida, ocorrendo a "adultotização da infância”, como abordado por Silva (2002, p. 151).

Trata-se de funções marcadas pela absoluta falta de proteção, segurança ou fiscalização, que expõem essas crianças a todo tipo de adversidades e de violência

\section{Discussão}

Ao analisar as situações, evidenciase o sofrimento de trabalhadores que, em decorrência do trabalho realizado em condição precária e sem qualquer tipo de proteção social ou legal, submetem-se a condições insalubres e perigosas por uma questão de subsistência.

Quanto à primeira situação, importa enfatizar que, historicamente, o trabalho rural foi garantido no patamar dos direitos sociais, trabalhistas e previdenciários de modo retardatário em relação ao urbano. ampliada pelo fato de serem realizadas, geralmente, no período noturno.

A violência a que crianças e adolescentes inseridos precocemente no mercado de trabalho estão sujeitos raramente é revelada nas estatísticas oficiais, pois dificilmente essas atividades se configuram como trabalho. Estão forjadas na "ajuda". A sociedade "ajuda" a criança e o adolescente pobres oferecendo-lhes um trabalho e esses, por sua vez, "ajudam" no orçamento familiar, trabalham oito horas diárias, às vezes mais, e recebem um salário de "ajuda", inferior ao do adulto que exerça a mesma função. Outra questão é que, diante da situação de base socioeconômica e de insuficiência das políticas públicas, o trabalho adquire um caráter disciplinador para crianças e adolescentes pobres (BRASIL, 2005). E, ainda, há de considerar que muitas doenças relacionadas ao trabalho só irão se manifestar na vida adulta, distanciando-se da relação com o trabalho, além de se configurar como forma de injustiça social banalizada cotidianamente.

As diferenças entre a infância no coletivo e as infâncias podem ser particularizadas em situações que envolvam o trabalho infantil, como abordado por Moreira e Vasconcelos (2003), que desconstroem a imagem idílica da criança - inocência, vivida em um mundo onírico, quimérico. A infância, no sentido coletivo, é um direito de todos, independentemente das circunstâncias socioeconômico-culturais; contudo, as espacialidades e os cotidianos em que as crianças estão submersas definem o tipo de infância que estas podem ter, individualizando-as.

Verifica-se que essas crianças estão imersas em condições inseguras para o seu desenvolvimento biopsicossociocultural.
Apenas a partir da Constituição de 1988, art. $7^{\circ}$, é equiparado ao trabalho urbano.

Mas, apesar da Carta Constituinte, as diferenças de tratamento entre os trabalhos urbano e rural, nos planos teórico e prático, ainda persistem, como é o caso da edição das Normas Regulamentadoras Rurais (NRR), específicas para a área rural. Mas salienta-se que as Normas Regulamentadoras (NR) e as legislações complementares contemplam esta categoria profissional, como defende Araújo (2005). 
Muitas das exigências contidas nas NR também estão presentes nas NRR, como é o caso dos Serviços Especializados em Prevenção de Acidentes do Trabalho Rural - SEPATR. Conforme o artigo $2^{\circ}$ da NRR-2, toda propriedade com 100 (cem) ou mais trabalhadores é obrigada a organizar e manter em funcionamento o SEPATR, que, diferentemente da NR-4, não tem uma classificação de grau de risco.

A explicação é que esta é uma norma específica para a atividade rural; logo, todos os graus de riscos são estimados como iguais. (ARAUJO, 2005, p. 1352)

Outra exigência da NRR a ser explicitada é a necessidade de formação e manutenção da Comissão Interna de Prevenção de Acidentes do Trabalho Rural (CIPATR) pelo empregador que mantenha a média de 20 ou mais funcionários, conforme previsto na NRR-3, artigo $3^{\circ}$ (ARAUJO, 2005).

Contudo, tanto a CIPATR quanto a SEPATR não são comuns no plano prático e um dos fatores que pode estar associado é a falta de fiscalização na área rural, bem como a ausência de dados estatísticos fidedignos quanto aos acidentes de trabalho dessa área.

Apesar de existirem instrumentos legais referentes à proteção da saúde dos(as) trabalhadores(as) rurais, muitos fatores interferem na falta de aplicação, como, por exemplo, a distância geográfica e/ou física dos órgãos públicos responsáveis pela sua efetivação. O elevado número de trabalhadores safristas e temporários, por sua vez, diminui a capacidade de organização do(a) trabalhador(a) rural agravada pela baixa escolaridade e também pela falta de informação dos seus direitos.

Verifica-se que Aparício realizava trabalho noturno, no âmbito agrícola, e, ao término da sua jornada, recebeu uma nova tarefa e não usufruiu o direito ao descanso preconizado na Legislação como garante o artigo 66 da Consolidação das Leis do Trabalho (BRASIL, 1943), o que pode ter se constituído em um dos fatores preponderantes para a ocorrência.

Trata-se de uma situação muito complexa, inclusive porque as condições de trabalho atualmente são outras, o que impede uma análise mais aprofundada. Mas questionam-se fatores que poderiam ter evitado o acidente ou não, por exemplo, a máquina dispunha de sistema de segurança adequado para o desligamento automático; no caso de mudança de posição do trabalhador, contava com dispositivo de fácil acesso para a interrupção do seu funcionamento e também apresentava proteção mecânica no ponto de operação, permitindo apenas a introdução do produto a ser moído; estava dentro dos prazos de manutenção preventiva?

As questões sobre a disposição da máquina no espaço físico, a proteção das intempéries, a organização do posto de trabalho e a área de estocagem da cana ou outro produto usado no feitio do alimento "trato" para o gado também devem ser ressaltadas, bem como as condições de instalação e do ambiente ("chão escorregadio").

Questões relacionadas à organização do trabalho, como a devida capacitação do trabalhador para desempenho da função, também devem ser consideradas. Além disso, o fato de ter saído de um posto de trabalho diferente do assumido sem o uso de Equipamento de Proteção Individual (EPI), como botas de PVC de solado antiderrapante e protetores auditivos para operar o trator (usado para arar terra) e a máquina (para moer o "trato" do gado), também é um fator contribuinte.

A discussão do acidente de trabalho no âmbito rural precisa ser alvo de estudos e ações sistemáticas devido ao grande número de acontecimentos, conforme levantamento feito na região de Franca por meio do Relatório de Atendimento aos Acidentes de Trabalho - RAAT (LOURENÇO \& BERTANI, 2006). Ressalta-se que, em julho de 2006, acidente semelhante ocorreu no município de Buritizal, circunvizinho a Franca-SP, deixando deficiente um jovem de 21 anos.

Verifica-se que a falta de articulação dos serviços públicos, especialmente aqueles relacionados aos Ministérios do Trabalho, da Saúde e da Previdência, contribui para que essas condições se mantenham na invisibilidade social. As precárias condições de trabalho ficam mascaradas e forjadas na insuficiência institucional do Estado frente à questão, especialmente na fragmentação das ações que, na situação analisada, consistem apenas na concessão de benefícios compensatórios insuficientes, como o previdenciário, uma vez que o trabalhador era contribuinte, e de saúde, por meio de tratamento e reconstituição do membro, no caso, a perna.

O tipo de acidente de trabalho sofrido por Aparício é um tipo “clássico” e que traz à mostra a perda do membro inferior 
(perna) e, em decorrência desta, a ruptura familiar, a exclusão do mercado de trabalho e a supressão de perspectivas de vida. Mas, além desse tipo de acidente de trabalho, há também a violência presente nos impactos das mudanças do mundo do trabalho, sobretudo na precarização das condições de trabalho, que a nosso ver afeta a saúde dos(as) trabalhadores(as) de modo oculto e silencioso.

Ao se refletir sobre a situação de uma família que sobrevive da atividade de catar lixo para posterior seleção e venda de materiais recicláveis, pretende-se evidenciar os riscos biopsicossociais inerentes à situação e sensibilizar sobre a importância de pesquisas e ações intersetoriais e interdisciplinares nesta área, como já destacado pela Organização Internacional do Trabalho (OIT, 2006).

Nesse tipo de trabalho, os riscos podem ser muitos. A OIT (2006), ao discutir o trabalho de crianças e adolescentes em lixão, aponta que se trata de uma atividade insalubre, perigosa e penosa, o que se aplica à situação apresentada, pois, além da atividade de coleta do lixo, a família, inclusive crianças, residia no local, em meio ao lixo, propensos a:

[...] possibilidades acentuadas de acidentes, intoxicações alimentares e químicas por metal pesado; infecções respiratórias, cutâneas, digestivas; desidratações, anemias por má nutrição, fadigas por esforço intenso e exposição a altas temperaturas do ambiente. (OIT, 2006, p. 69)

O fórum "Lixo e Cidadania” aponta que, em 1998, quando houve intoxicação alimentar de crianças devido à possível ingestão de carne humana proveniente de lixo hospitalar, num lixão em Olinda-PE, iniciou-se o esforço de várias instituições na busca de resolver a questão, constituindo inclusive o "Fórum Nacional Lixo e Cidadania” (FÓRUM, 2006).

Outros riscos, como a contaminação do ambiente (solo, ar e água), devem ser considerados, pois se observou que o local era propício para diversos vetores causadores de enfermidades, como ratos, moscas, baratas, só para citar alguns.

Na terceira situação, evidenciou-se o trabalho infantil inserido no mercado de trabalho, no modo da economia considerado informal, que, diante da sua proibição legal, assume também o caráter clandestino, além da questão cultural da "ajuda”.
Verificou-se nas situações que a infância e a adolescência, tão importantes para a formação social e emocional da vida humana, são vividas por muitos sem usufruto dos direitos e privilégios próprios dessa faixa etária. A obrigação de “ajudar” no orçamento familiar deixa a escola para um período posterior e talvez inatingível, bem como o lazer e as brincadeiras. A sua marca é a exploração, que, reforçada pela desigualdade social, adquire um caráter de algo "natural”, pois, após conversar e observar o trabalho das crianças por horas, num local movimentado, ninguém questionou ou denunciou a presença delas e o seu trabalho.

O trabalho projeta o ser humano para perspectivas profissionais, sociais e para a realização pessoal, mas quando há a inserção precoce, além dessas perspectivas ficarem tolhidas, pode ocorrer o que Martins (1993) chamou de supressão da infância. O trabalho infanto-juvenil tornou-se um fenômeno social da pobreza e geralmente ocorre em condições insalubres e danosas para o desenvolvimento biopsicossociocultural de crianças e adolescentes, como já abordado por Garbin, Santos e Carmo (2004).

Asmus et al. (2005) discutem que muitas atividades, apesar de seguras para os adultos, não o são para as pessoas em crescimento que têm maiores chances de desenvolver doenças ocupacionais, tanto de forma mais precoce quanto com maior gravidade. Chamam a atenção para o fato de que o dano pode não ser evidente até um estágio bastante posterior da vida (ATSDR, 2001 apud ASMUS et al., 2005).

As situações apresentadas a partir de observações do cotidiano revelam que o trabalho infantil ainda persiste revestido de uma nova roupagem: a informalidade. Os dados da Pesquisa Nacional por Amostragem de Domicílios (PNAD), referentes ao período de 1992 a 2002, mostram que o número de trabalhadores infantis reduziu de 4,1 milhões em 1992 (12,1\%) para 2,1 milhões em 2002 (6,5\%), na faixa etária de 5 a 14 anos (BRASIL, 2004).

Reconhece-se a avançada legislação voltada à redução e à erradicação do trabalho infantil vigente em nosso país, como o Estatuto da Criança e Adolescente - ECA (BRASIL, 1990a), a Constituição Federal ${ }^{3}$ e a Consolidação das Leis Trabalhistas $(\mathrm{CLT})^{4}$. Destaca-se que ao adolescente só é permitido trabalhar dos 14 aos 16 anos na condição de aprendiz e deve ser respeitada
${ }^{3}$ Redação dada pela Emenda Constitucional n. 20 de 15/12/1998.

${ }^{4}$ Capítulo IV - Da proteção do trabalho do menor: Art.403 (redação dada pela lei n. 10097/2000); Art. 404; Art. 405 (redação dada pela Lei n. 10097/2000). 
a proibição em situações e condições inseguras capazes de provocar acidentes.

Contudo, as situações ilustradas mostram que o trabalho infantil ainda persiste e que também se verifica, no nosso cotidiano profissional, em relação à incidência de acidentes de trabalho com adolescentes (LOURENÇO, 2006).

As condições de saúde podem ser consideradas como expressões da questão social, representada, neste caso, pelo trabalho sem nenhuma regulamentação e segurança que expõe crianças à situação de riscos. Além dos riscos eminentes, consideram-se os riscos sociais, como a exclusão social, marcada pelo distanciamento dos direitos sociais básicos: educação, saúde e habitação. Não se trata apenas de apontar situações, do ponto de vista da saúde, intoleráveis, capazes de causar danos físicos e psíquicos, mas de situar no âmbito da exploração do trabalho e das ordens social, econômica e política vigente e, portanto, passíveis de transformação.

Verifica-se que as precárias condições de trabalho, ora apresentadas, fazem parte da histórica desigualdade social brasileira e, neste contexto, assumem um caráter de

\section{Conclusões e considerações finais}

Verifica-se que, apesar do avanço das políticas públicas, dos direitos sociais, trabalhistas e políticos, das exigências para a troca, especialmente, no âmbito internacional, caracterizadas pelos Programas de Qualidade Total e pelas International Standard Organization (ISO) nesse início de século (XXI), novas e velhas questões relativas à saúde e ao trabalho (MINAYO GOMES \& LACAZ, 2005) se põem no cotidiano dos(as) trabalhadores(as).

Análises da realidade que busquem esclarecer os efeitos das formas de trabalho associadas à informalidade, velhas questões como as condições de trabalho rural, a erradicação do trabalho infantil e, ainda, a proteção do trabalho do adolescente, assumem caráter de urgência em que pese a relação entre trabalho/saúde. algo natural e, como tal, oferecem poucas perspectivas de mudanças.

O fato é que, diante das desigualdades sociais vinculadas ao desemprego e à exclusão, acaba ocorrendo o que Dejours (2005) denominou de "banalização da injustiça social”. Há uma "aceitação" social do que está posto. Esta conivência se dá pela compreensão da realidade como algo natural que, somado ao aspecto cultural do trabalho infantil como elemento disciplinador e preventivo da marginalidade, quando se trata dos mais pobres, constitui elementos mantenedores desta (triste) realidade.

Nobre (2003) pontua que o trabalho infantil deve se tornar objeto da saúde coletiva e sublinha algumas limitações do setor saúde frente a esta questão: evidencia a falta de reconhecimento do trabalho infantil como um problema de saúde pública; indica que o trabalho infantil é invisível para as práticas de saúde, quando o reconhece, situa-o no patamar de resolução para o problema da miséria social.

Para que a relação entre saúde e trabalho não caia na invisibilidade social, é necessário reunir esforços para estudos e ações sistemáticos que contemplem o mercado de trabalho na sua totalidade e considerem os trabalhos rural, informal e infantil.
A saúde pública já presta o atendimento ao trabalhador vítima de doença ou de acidente relacionado ao trabalho e conta com serviços especializados de vigilância sanitária e epidemiológica. Contudo, há necessidade de romper com as ações focais e fragmentadas na assistência à saúde do(a) trabalhador(a) e avançar na construção de dados fidedignos para subsidiar ações mais amplas.

Posto o desafio, o campo ampliado da saúde do trabalhador no SUS constitui um novo paradigma de atenção à saúde, transcende a abordagem individual curativa tradicional e propõe abordagens interdisciplinares, intersetoriais e de fortalecimento da sociedade rumo a mudanças eficazes para a promoção da saúde de quem trabalha. 


\section{Referências}

AMMANN, S. B. Cidadania e exclusão social: o mundo desenvolvido em questão. Serviço Social \& Sociedade, São Paulo, n. 76, p. 118-142, 2003.

ASMUS, C. I. R. F. et al. Atenção integral à saúde de adolescentes em situação de trabalho: lições aprendidas. Ciênc. saúde coletiva, Rio de Janeiro, v. 10, n. 4, p. 953 -959, 2005.

ANTUNES, R. Adeus ao trabalho? Ensaio sobre as metamorfoses e a centralidade do mundo do trabalho. 6. ed. São Paulo/ Campinas: Cortez/Unicamp, 1999.

ARAUJO, G. M. (Org.). Normas Regulamentadoras comentadas. Legislação de Segurança e Saúde no Trabalho.

rev., ampl. e atual. Rio de Janeiro:

Gerenciamento Verde, 2005. v. 1 e 2.

BRASIL. Decreto-Lei n. ${ }^{\circ} 5.452$, de $1^{\circ}$ de maio de 1943. Aprova a Consolidação das Leis do Trabalho (CLT). Disponível em: https://www.planalto.gov.br/ccivil_03/ decreto-lei/Del5452.htm. Acesso em: 02 jan. 2007.

. Constituição da República

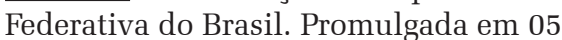
de outubro de 1988. Brasília, DF: Senado, 1988.

Estatuto da Criança e do Adolescente. Lei 8 069, de 13 de julho de 1990a. Dispõe sobre o Estatuto da Criança e do Adolescente e dá outras providências. Brasília, DF: Senado, 1990.

. Lei Orgânica da Saúde - LOS

(1990b). In: COSTA, L. C. (Org.). Cadernos de Saúde do Trabalhador: Legislação. Brasília, DF: Ministério da Saúde, 2001.

. Lei n. 8.213. Dispõe sobre os Planos de Benefícios da Previdência Social e dá outras providências. Ministério da Previdência Social, Brasília, DF., 24 de julho de 1991. DOU de 14/08/98. (Atualizada até julho de 2005). Disponível em: http://www.planalto.gov.br/CCIVIL/ Leis/L8213cons.htm. Acesso em: 5 jan. 2007.

Portaria Federal n ${ }^{\circ}$ 1.339/GM - MS - (1999). Brasília, DF.: Ministério da Saúde, de 18 de novembro de 1999.
Disponível em: http://bvsms.saude.gov.br/ html/pt/legislacao/portarias.html. Acesso em: 05 jan. 2007.

. Portaria $\mathrm{n}^{\mathrm{o}}$. 1.679, de 20 de

setembro de 2002. Brasília, DF: Ministério da Saúde, 2002.

Plano Nacional de Prevenção

e Erradicação do Trabalho Infantil e Proteção ao Trabalhador Adolescente. Brasília: Ministério do Trabalho e Emprego, Secretaria de Inspeção do Trabalho, 2004.

. Trabalho Infantil: diretrizes para a atenção integral à saúde de crianças e adolescentes economicamente ativos. Brasília: Ministério da Saúde, 2005.

COHN, A.; KARSCH, U. S.; SATO, A. K. Acidentes de trabalho: uma forma de violência. São Paulo: Brasiliense, 1985.

DEJOURS, C. A banalização da injustiça social. Rio de Janeiro: FVG, 2005.

DIAS, E. C. (Org.). Doenças relacionadas ao trabalho: manual de procedimentos para os serviços de saúde. Brasília, DF: Ministério da Saúde, 2001. Série A. Normas e manuais técnicos.

DIAS. E. C.; HOEFEL, M. da G. O desafio de implantar as ações de saúde do trabalhador no SUS: a estratégia da RENAST. Ciênc. saúde coletiva, Rio de Janeiro, v. 10, n. 4, p. 817-828, 2005.

ENGELS, F. A situação da classe trabalhadora na Inglaterra. São Paulo: Global, 1985. (Coleção Bases, 47).

\section{FÓRUM NACIONAL LIXO E}

CIDADANIA. Disponível em: http://www. lixoecidadaniapr.org.br/forunII.htlm. Acesso em: 29 dez. 2006.

GARBIN, A. de C.; SANTOS, S. A. do; CARMO, J. C. Caracterização da situação estadual do trabalho de crianças e adolescentes no estado de São Paulo. In: GARBIN, A. de C.; SANTOS, S. A. do (Orgs.). O compromisso do SUS na erradicação do trabalho de crianças e controle do trabalho de adolescentes. São Paulo: Imprensa Oficial, CEREST/SP, 2004. p. 13-44. 
LACAZ, F. A. C. Saúde do trabalhador: um estudo sobre as formações discursivas da academia, dos serviços e do movimento sindical. 1996. Tese (Doutorado)

- Faculdade de Ciências Médicas, Universidade Estadual de Campinas, Campinas, 1996.

Saúde dos trabalhadores: cenários e desafios. Cad. Saúde Pública, Rio de Janeiro, v. 13, supl. 2, p. 7-19, 1997. Disponível em: http://www.scielo. br/scielo.php?script=sci. Acesso em: 27 jan. 2005

LOURENÇO, E. A. S. Acidentes de trabalho com adolescentes e a necessidade do trabalho intersetorial. In: SEMINÁRIO DE ERRADICAÇ̃̃O DO TRABALHO INFANTIL E PROTEÇÃO DO TRABALHO DO ADOLESCENTE: uma proposta de ação intersetorial. Franca, 2006. (mimeo).

. Saúde do trabalhador: de quem é essa responsabilidade? Desafios para o Sistema Único de Saúde. In: OLIVEIRA, C. A. H; BERTANI, I. F. Interdisciplinaridade: integração entre saberes e práticas. Franca: Unesp, 2006.

MARTINS, J. de S. (Coord.). O massacre dos inocentes: a criança sem infância no Brasil. 2. ed. São Paulo: Hucitec, 1993.

MINAYO GOMEZ, C.; LACAZ, F. A. C. Saúde do trabalhador: novas e velhas questões. Ciênc. saúde coletiva, Rio de Janeiro, v. 10, n. 4, p 797-807, 2005.

MOREIRA, E. M.; VASCONCELOS, K. E. L. Infância, infâncias: o ser crianças em espaços socialmente distintos. Serviço Social \& Sociedade, São Paulo, n. 76, p. 165-180, 2003.

NOBRE, L. C. C. Trabalho de crianças e adolescentes: os desafios da intersetorialidade e o papel do Sistema Único de Saúde. Ciênc. saúde coletiva, Rio de Janeiro, v. 8, n. 4, p. 963-971, 2003.

OIT. Organização Internacional do Trabalho. Módulos de auto-aprendizagem sobre saúde e segurança sobre o trabalho infanto-juvenil. Brasília: Ministério da Saúde, 2006. (Série F. Comunicação e educação em saúde).

POCHMANN, M. Desempregados do Brasil. In: ANTUNES, R. (Org.). Riqueza e miséria no Brasil. São Paulo: Boitempo, 2006. p. 59-73.

SILVA, M. L. de O. S. Adultotização da infância: o cotidiano das crianças trabalhadoras no mercado Ver-o-Peso, em Belém do Pará. Serviço Social e Sociedade, São Paulo, n. 69, p. 151-172, 2002.

VILELA, R. A. G. Desafios da vigilância e da prevenção de acidentes do trabalho. São Paulo: LTr, 2003. 